\title{
The Limits of Helium Cooling in Fusion Reactor First Walls and Blankets
}

C.W. Stewart

M.C.C. Bampton

D. T. Aase

A.M. Sutey

January 1978

Prepared for the

U.S. Department of Energy

under Contract EY-76-C-06-1830 


\title{
NOTICE
}

This report was prepared as an account of work sponsored by the United States Government. Neither the United States nor the Department of Energy, nor any of their employees, nor any of their contractors, subcontractors, or their employees, makes any warranty, express or implied, or assumes any legal liability or responsibility for the accuracy, completeness or usefulness of any information, apparatus, product or process disclosed, or represents that its use would not infringe privately owned rights.

The views, opinions and conclusions contained in this report are those of the contractor and do not necessarily represent those of the United States Government or the United States Department of Energy.

\author{
PACIFIC NORTHWIEST LABORATORY \\ operated by \\ BATTELLE \\ for the \\ UNITED STATES DEPARTMENT OF ENERCY \\ Under Contract EY-76-C-06-1830
}

\author{
Printed in the United States of America \\ Available from \\ National Technical Information Service \\ United States Department of Commerce \\ 5285 Port Royal Road \\ Springfieid, Virginia 22157
}

Price: Printed Copy $\$$ : Microtiche $\$ 3.00$

NTIS

*Pages

Selling Price

$001-025$

$026-050$

$051-075$

$076-100$

$101-125$

$126-150$

$151-175$

$176-200$

$201-225$

$226-750$

$251-225$

276-300

$\$ 4.50$

$\$ 5.00$

$\$ 5.50$

$\$ 6.00$

$\$ 6.50$

$\$ 7.00$

5775

$\$ 8.50$

33.75

59.00

510.00

$\$ 10.25$ 
THE LIMITS OF HELIUH COOLING

IN FUSION REACTOR

FIRST WALLS AND BLANKETS

\author{
by \\ C. W. Stewart \\ M. C. C. Bampton \\ D. T. Aase \\ A. M. Sutey
}

January 1978

BATTELLE

Pacific Northwest Laboratories Richland, Washington 99352 


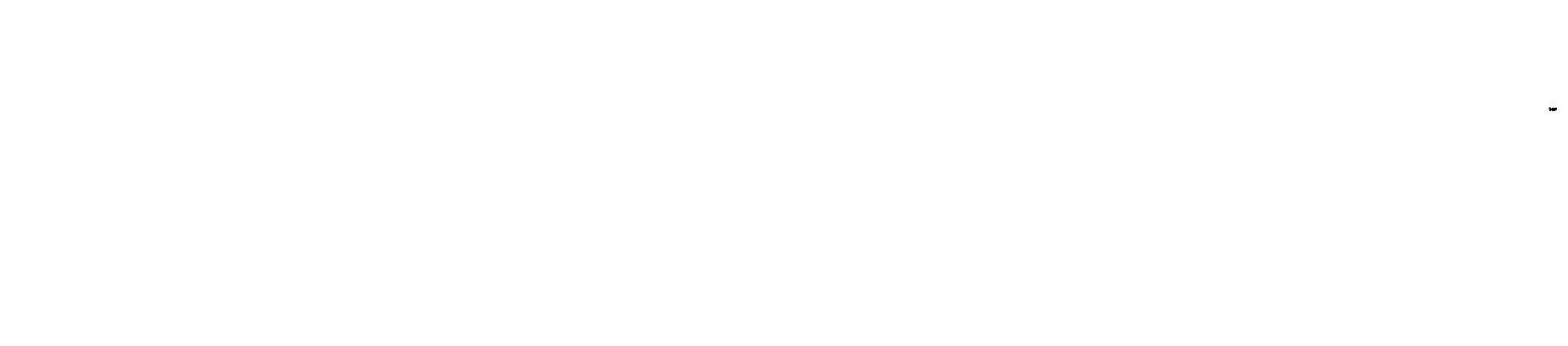




\section{CONTENTS}

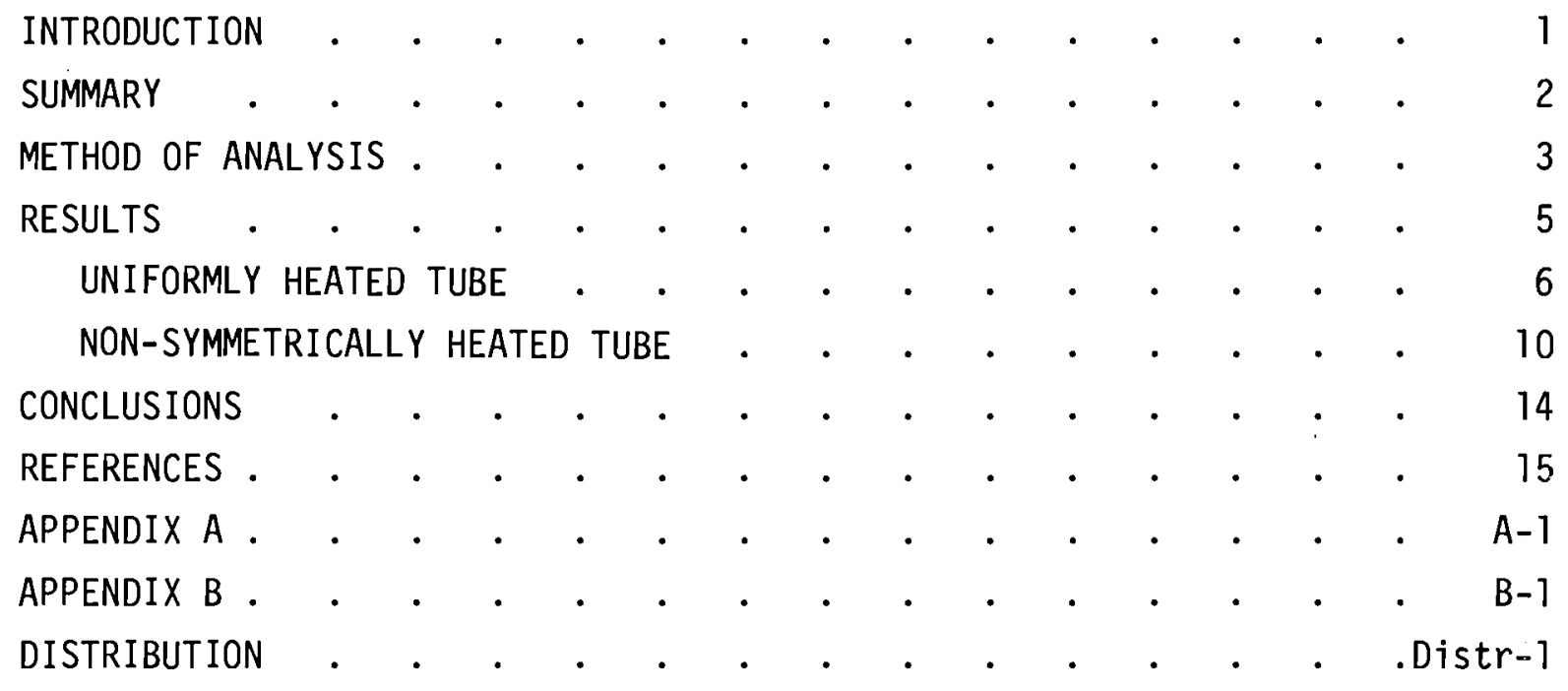




\section{$\underline{\text { LIST OF FIGURES }}$}

1 Heat Flux versus Length with Diameter Variation for Symmetric Heating

2 Heat Flux versus Length with Pressure Variation for Symmetric Heating . $\cdot \begin{gathered}\text {. } \\ \text {. }\end{gathered}$

3 Stress Limited Heat Flux versus Pressure for

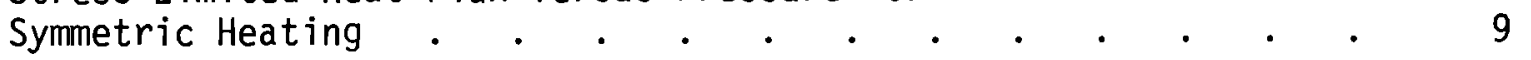

4 Heat Flux versus Length with Diameter Variation for Non-Symmetric Heating . . . . . . . . . . . 11

5 Heat Flux versus Length with Pressure Variation for Non-Symmetric Heating . . . . . . . . . . . 12

6 Stress Limited Heat Flux versus Pressure for Non-Symmetric Heating . . . . . . . . . . . 13

A-1 Geometry and Temperature Variation for an Externally Heated Tube .

B-1 Temperatures and Stresses for a Uniformly Heated Tube . . . B-2

B-2 Temperatures and Stresses for a Non-Symmetrically Heated Tube 
THE LIMITS OF HELIUM COOLING IN FUSION REACTOR

FIRST WALLS AND BLANKETS

\section{INTRODUCTION}

Helium is an attractive coolant candidate for fusion reactor first walls and blankets for several important reasons:

- Helium flow is not affected by intense, transient magnetic fields as are liquid metals.

- Since helium is chemically inert, it does not present the extreme fire hazard of liquid metals nor the corrosion problems of water.

- As an ideal gas, phase change difficulties such as water boiling and liquid metal freezing are avoided.

- Helium can potentially be used directly to power turbogenerators for higher power plant efficiency.

Arguments against helium or any gas coolant as opposed to water or liquid metals center around its lower heat capacity and surface heat transfer rate and the requirement of high operating pressure to achieve adequate heat transfer and a practical pumping power. On the balance, however, helium is certainly an adequate cooling medium as has been shown by its HTGR application and its use in several fusion reactor concepts. (1-5)

None of these applications approach the ultimate capability of helium cooling because their operating conditions are determined by other interrelated design objectives. The shape and size of the duct may be set by neutronics or the duct length restricted by the placement of neutral beam ports to less than optimum values. 
This study avoids these obstacles by exploring the practical limits of helium cooling in a simple geometry unconstrained by a particular conceptual design. Specifically, the configuration was chosen to be an externally heated straight tube considering both uniform heating and heating of half the external perimeter. Both thermal hydraulic and structural limits to the heat flux have been investigated.

Curves are presented to show the heat flux and tube length which simultaneously attain both a wall temperature and pressure drop/pumping power 1 imit for a range of diameters from 0.05 to 8.0 inches and pressures from 50 to $5000 \mathrm{psia}$. Tube wall stress limits on heat flux are also shown for the same range of pressure and diameter. These results should serve as an aid in planning more complex concepts as well as evaluating helium cooling in this specific configuration.

\section{SUMMARY}

The results of this investigation show that under the proper conditions helium can achieve heat fluxes comparable to boiling water systems. However, thermal stresses will limit heat flux more often than the coolant, particularly when the heating is non-uniform.

Consider a practical sized section of coolant tube $20 \mathrm{ft}$ long and about 1.5 inches inside diameter. At a helium pressure of 1000 psi the uniformly heated tube can support a heat flux of $320,000 \mathrm{Btu} / \mathrm{hr}-\mathrm{ft}^{2}$ [just over $1 \mathrm{MW}(\mathrm{t}) / \mathrm{m}^{2}$ ] before reaching the limiting wall temperature of $1000^{\circ} \mathrm{F}$ and pressure drop of $50 \mathrm{psi}$. The temperature/pressure drop limited heat flux decreases approximately linearly with pressure and diameter.

If the length were reduced below $12 \mathrm{ft}$, the heat flux could be increased until it became limited by thermal stress to approximately $480,000 \mathrm{Btu} / \mathrm{hr}^{-\mathrm{ft}^{2}}$ $\left.\left[01.5 \mathrm{MW}(t) / \mathrm{m}^{2}\right)\right]$. Assuming a sufficiently short tube to avoid the wall temperature/pressure drop limit, the stress limited heat flux decreases with decreasing pressure but increases with decreasing diameter because of the reduced wall thickness requirement. 
Thermal stresses are a much more severe restriction if the tube is heated over only half its perimeter as it might be in a fusion reactor first wall application. The $20 \mathrm{ft}, 1.5$ inch I.D. tube would be stress 1 imited to only $65,000 \mathrm{Btu} / \mathrm{hr}-\mathrm{ft}^{2}\left[\sim 0.2 \mathrm{MW}(\mathrm{t}) / \mathrm{m}^{2}\right]$ which is about one fifth the capacity of the uniformly heated tube. However, since only half the heat enters per unit length at a given heat flux, the non-uniformly heated tube may be twice as long as the uniformly heated tube. The non-uniformly heated tube could be lengthened to $125 \mathrm{ft}$ before becoming temperature/pressure drop limited at $65000 \mathrm{Btu} / \mathrm{hr}-\mathrm{ft}^{2}$.

It is important to note that the thermal stress 1 imits apply regardless of what coolant is being used. Therefore, in non-symmetrically heated situations, such as the first wall, the mechanical design of the wall is probably much more important than the choice of coolant.

\section{METHOD OF ANALYSIS}

Three independent aspects determine the maximum heat flux attainable from a convectively cooled surface:

- The maximum allowable surface or duct wall temperature.

- The maximum pumping power or pressure head available to drive the cooling fluid over the surface.

- The maximum allowable steady and cyclic thermal stresses in the duct wall. In designing an entire cooling system, only one of these is usually $7 \mathrm{im}-$ iting since the length and diameter of the coolant passage is fixed by other considerations. If the coolant duct dimensions are allowed to vary arbitrarily, however, the heat flux and dimensional combination which meets at least the first two 1 imiting conditions simultaneously may be determined. Further increases in heat flux beyond this point require a reduction in duct length until the point of maximum heat flux is reached in one of two ways: 
1. Assuming the duct wal1 thickness is prescribed by the internal pressure, a limiting steady or cyclic thermal stress level is reached.

2. A hypothetical "zero length" is reached at which the surface temperature at the duct inlet already exceeds the maximum and no further heat addition is possible.

The locus of points where either of these limits occurs for a range of pressure and lateral duct dimension defines the surface of maximum possible heat flux attainable through the surface under the given temperature, $\Delta \mathrm{P} /$ power and stress limits.

The shape of the duct and its thermomechanical properties have a direct influence on the maximum heat flux. In order to reduce the amount of data to be generated, this study will be limited to circular tubes of stainless steel which is typical of many proposed state-of-the-art concepts. The $1 \mathrm{im}$ iting pressures, temperatures and stresses chosen for this configuration are listed in Table 1. Stress limits are prescribed by the ASME code. ${ }^{(6)}$ Both uniform internal heating and the case of $1 / 2$ the perimeter heated wi11 be considered.

TABLE 1. Limiting Values Chosen for an Externally Heated, Helium Cooled Stainless Steel Tube

Limit
Wall temperature (outer
surface at tube exit)
Pressure head
Pumping power
Tensile stress, $\sigma_{\mathrm{m}}$
Steady thermal stress
and tensile stress
Cyclic component of
thermal stress for
infinite life

$\frac{\text { Value }}{1000^{\circ} \mathrm{F}}$

$1 \%$ operating pressure

$5 \%$ of thermal power

15,000 psi

$3 \sigma_{m}$

10,500 psi 
The range of operating conditions considered is limited to approximately the state of the art also. It is assumed that the helium is driven through a secondary heat exchanger (steam generator) by a circulator of roughly HTGR configuration rather than any advanced direct cycle. The operating conditions chosen are inlet temperature, pressure, and heat flux and tube diameter. The base case and range of values considered for these operating parameters are listed in Table 2.

\section{TABLE 2. Operating Conditions}

\begin{tabular}{|c|c|c|}
\hline QUANTITY & BASE VALUE & RANGE \\
\hline Inlet temperature & $300^{\circ} \mathrm{F}$ & not varied \\
\hline Pressure & 1000 psi & $50-5000$ ps $i$ \\
\hline Heat flux & --- & $6\left(10^{3}\right)-6\left(10^{5}\right) \mathrm{btu} / \mathrm{hr}-\mathrm{ft} \mathrm{t}^{2}$ \\
\hline Tube diameter & $1.47 \mathrm{in.}$ & $0.05-8.0 \mathrm{in.}$ \\
\hline
\end{tabular}

The tube length and inlet mass flux required to meet the inside surface temperature and pumping power/pressure head limits simultaneously for a given heat flux, tube diameter and operating pressure are found by solving the onedimensional steady-state conservation equations for mass, energy and momentum. The heat flux and inside surface temperature are adjusted to satisfy the thermal stress limiting criteria and maximum outside wall temperature. The equations used to perform these calculations are derived in appendices $A$ and $B$, respectively. A computer program, HOTGAS, has been constructed to incorporate this procedure with the necessary logic to vary the diameter and operating conditions for parametric studies.

\section{RESULTS}

The quantitative results of this study consist of the tube length $L$, and heat flux, q", necessary to satisfy the given temperature and pressure drop limits. These curves of $q^{\prime \prime}$ vs. $L$ are presented for a range of diameters at a constant base pressure and also for a range of pressures at a base diameter. The stress limiting surface for all diameters and pressures is also shown. Refer again to Tables 1 and 2 for the limits and range of operating conditions. Results for a uniformly heated tube will be presented first. 


\section{UNIFORMLY HEATED TUBE}

Consider first the q" vs. L curves at a constant pressure of 1000 psi with tube diameter range of 0.05 to 8 inches shown in Figure 1.

Interpreting the figure at a diameter of 1.47 in. and heat flux of $10,000 \mathrm{Btu} / \mathrm{hr}^{-\mathrm{ft}^{2}}$ the maximum pressure head will drive a sufficient flow rate through a length of 3300 inches so that the outside surface temperature at the tube exit will be the limiting value of $1000^{\circ} \mathrm{F}$. If the heat flux is increased holding the same diameter, the length must decrease to stay at the temperature limit. The shorter length produces less drag and the mass flux increases. Heat flux can continue to increase up to approximately $480,000 \mathrm{Btu} / \mathrm{hr}^{-\mathrm{ft}^{2}}$ at this diameter before the maximum thermal stress occurs. The figure indicates that higher heat fluxes can be obtained with smaller diameters and a corresponding decrease in length.

Performance variation with pressure at a constant 1.47-inch diameter is shown in Figure 2. Note that a 1000 psi curve in Figure 2 would correspond exactly to the 1.47-inch diameter curve on Figure 1. On both figures, an increase in heat flux at a constant pressure and diameter requires a decreased length. At any given length, higher pressure will allow a significantly higher heat flux until the stress limit is reached. For a practical tube length of 8 to 20 feet, a pressure range of 650 to 1200 psi would be most efficient. Use of a higher pressure would actually lower the maximum attainable heat flux. A lower pressure on the other hand, would raise the heat flux but only if the length were much reduced.

This behavior is more evident on Figure 3 which is the stress limit surface for the entire range of pressure and diameter. The area enclosed by the dash 7 ine on the figure represents the currently practical design range of 650 to 1200 psi pressure and from 0.25 to 1.5 inches diameter. Note that the maximum heat fluxes possible are on the order of $10^{6} \mathrm{Btu} / \mathrm{hr}-\mathrm{ft}^{2}$ which compares quite favorably with the highest heat fluxes attainable with boiling water. 


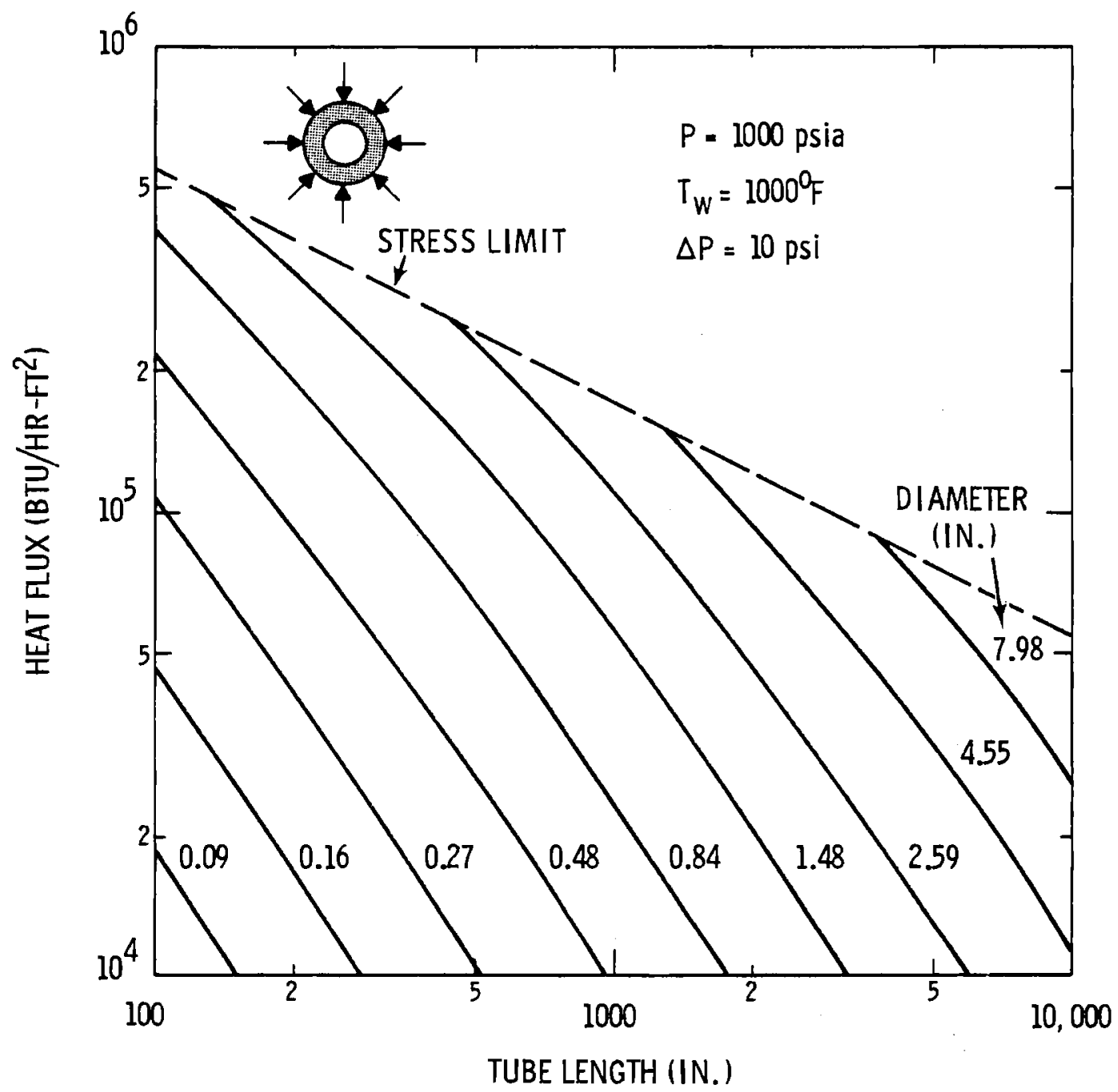

FIGURE 1. Heat Flux versus Length with Diameter Variation for Symmetric Heating 


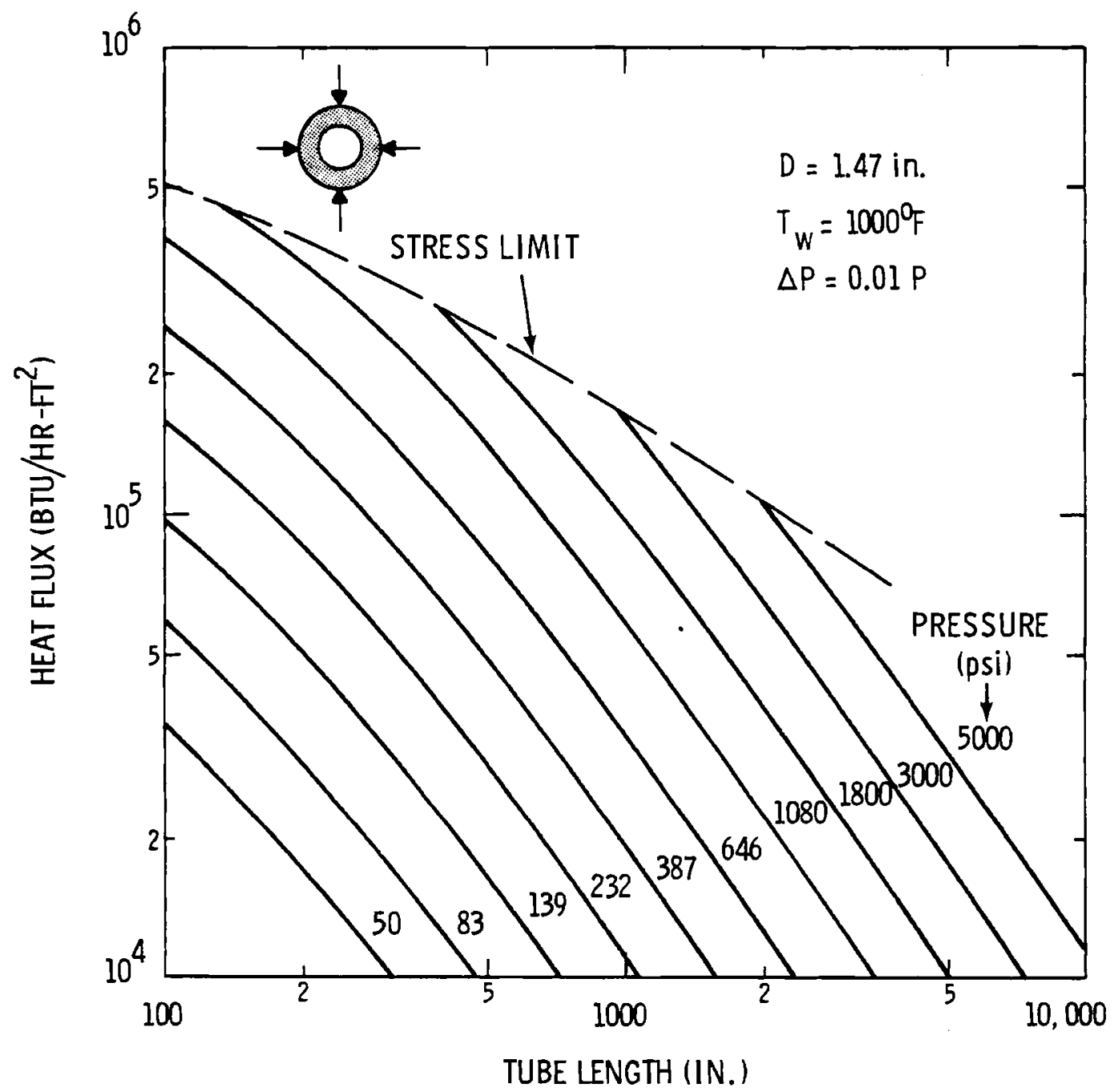

FIGURE 2. Heat Flux versus Length with Pressure Variation for Symmetric Heating 


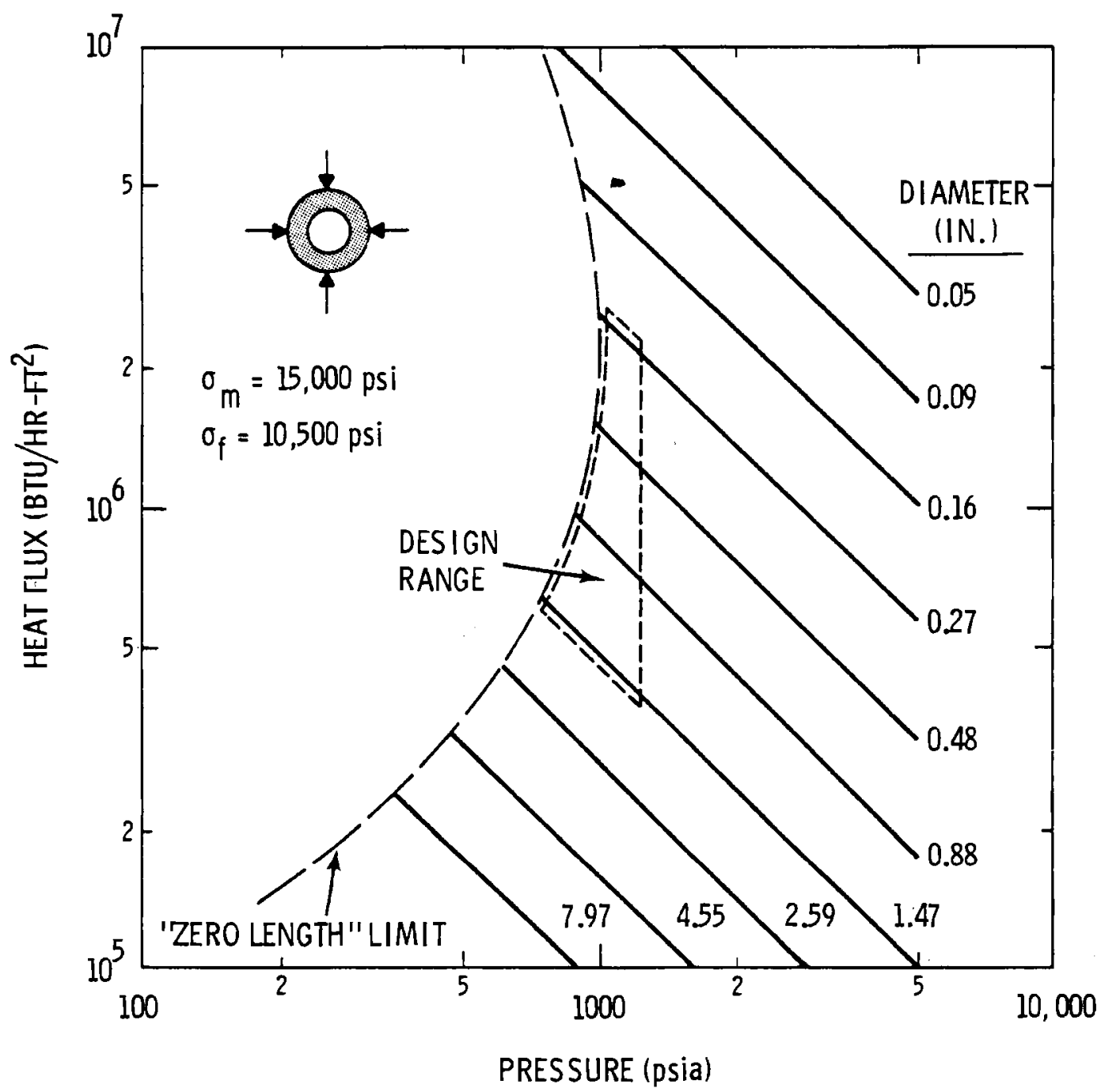

FIGURE 3. Stress Limited Heat Flux versus Pressure for Symmetric Heating 
NON-SYMMETRICALLY HEATED TUBE

In this case, one half the tube perimeter is heated as it might be in a first wall application. This places an additional bending stress in the tube wall with the heated half in compression and the unheated half in tension. The same family of curves as for the uniformly heated tube are shown in Figures 4,5 and 6 . Below the stress limits the trends are the same as for the uniformly heated tube. The only significant change is that the length may be made longer since only $1 / 2$ the total heat is getting into the fluid. At the stress limit, however, the behavior is quite different.

By following the 0.479-inch diameter line on Figure 6 it can be seen that the maximum heat flux increases with increasing pressure up to a value of about 120,000 Btu/hr- $\mathrm{ft}^{2}$ at about $2000 \mathrm{psi}$ and then decreases again as the pressure further increases. This implies an "ideal pressure" for any given diameter at which the thermal stress limitation is least severe. This assumes that the tube wall is just thick enough to withstand the internal pressure. Below the "ideal pressure" it would actually be advantageous to make the tube wall thicker than necessary in order to present a larger area to the bending load produced by non-symmetric heating.

Whatever pressure is used, a comparison of the practical design range in Figures 3 and 6 shows immediately that there is a severe penalty for nonsymmetric heat flux due to thermal stresses. The maximum heat flux within the design range in Figure 3 is over $2.5\left(10^{6}\right) \mathrm{Btu} / \mathrm{hr}-\mathrm{ft}^{2}$ (over $50 \mathrm{MW} / \mathrm{m}^{2}$ neutron loading) while the design range for the non-symmetric case in Figure 6 is below $150,000 \mathrm{Btu} / \mathrm{hr}^{-\mathrm{ft}^{2}}$ (equivalent to about $3.2 \mathrm{MW} / \mathrm{m}^{2}$ neutron loading). Admittedly, the case analyzed is conservative but it indicates that wall design may easily limit heat transfer more often than the choice of coolant. 


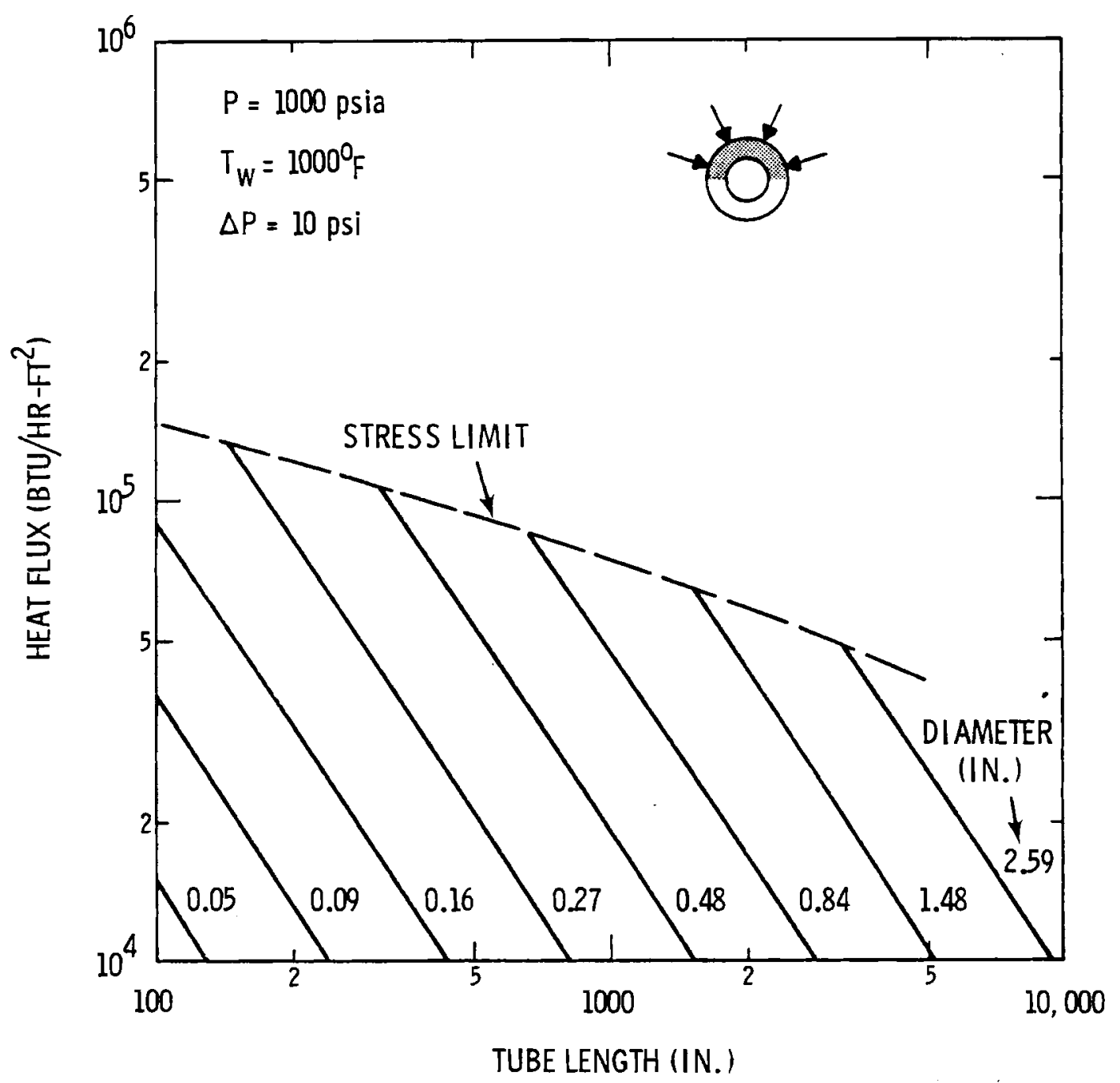

FIGURE 4. Heat Flux versus Length with Diameter Variation for Non-Symmetric Heating 


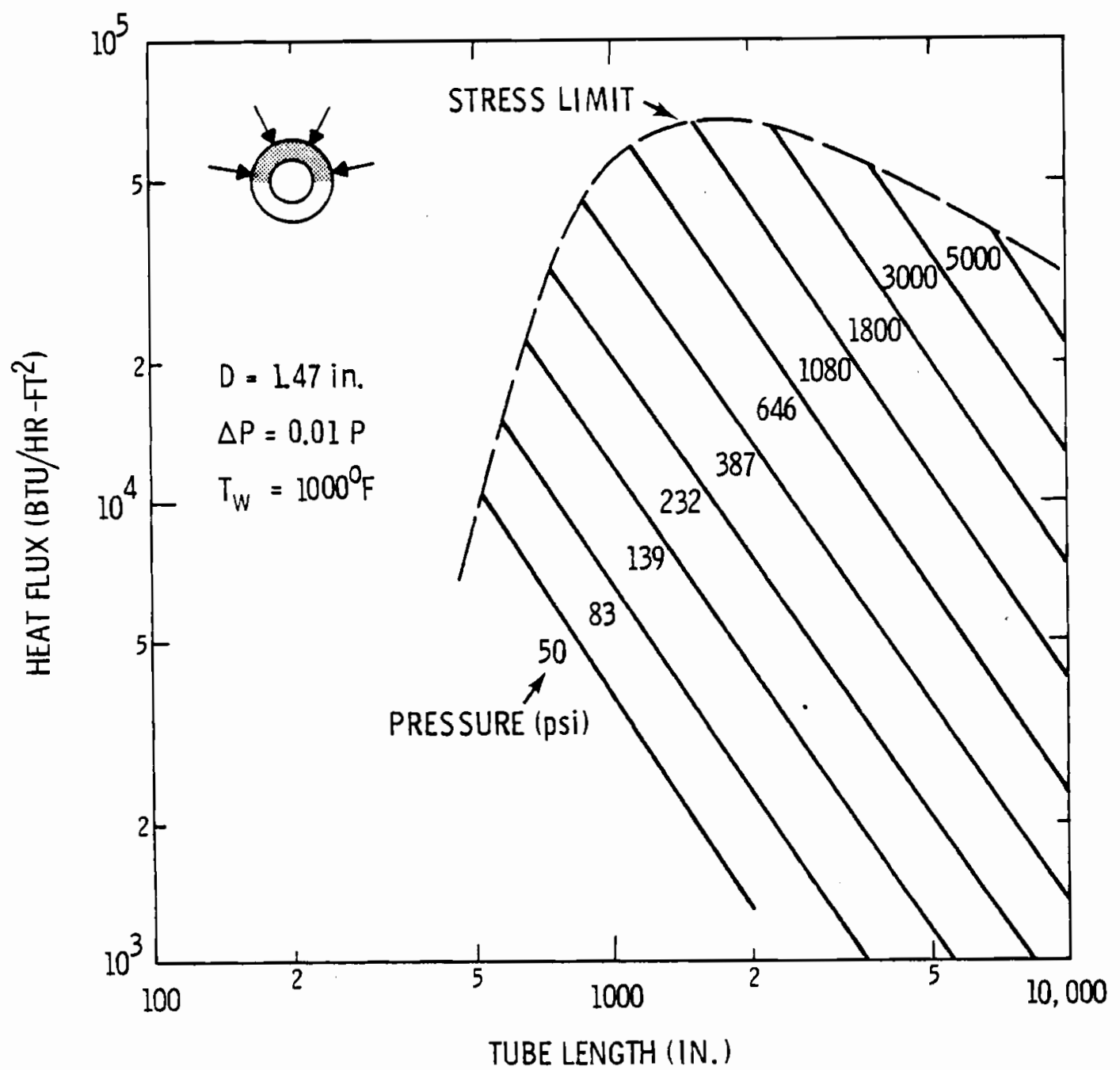

FIGURE 5. Heat Flux versus Length with Pressure Variation for Non-Symmetric Heating 


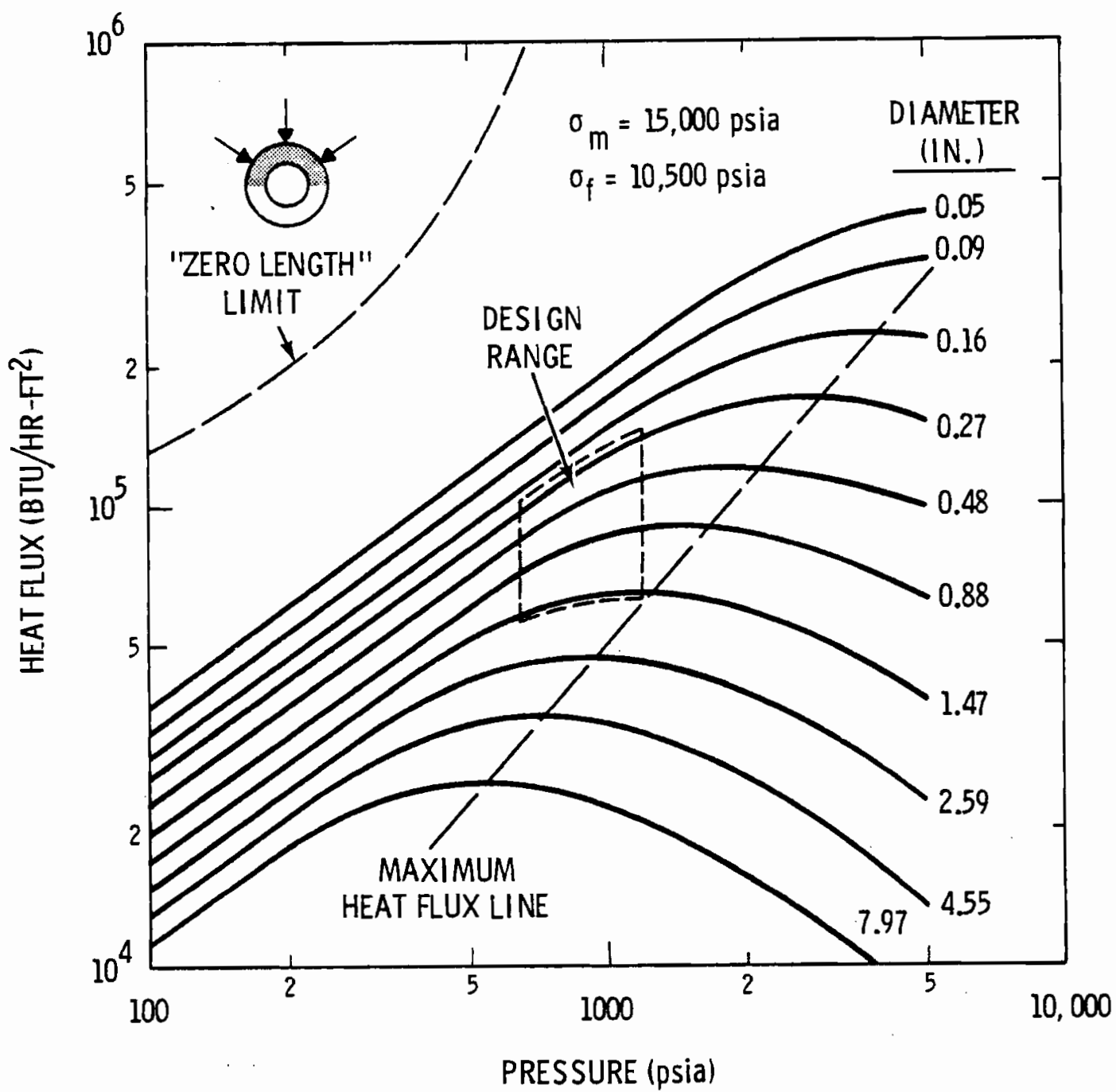

FIGURE 6. Stress Limited Heat Flux versus Pressure for Non-Symmetric Heating 


\section{CONCLUSIONS}

The results of this analysis show that the use of helium as a coolant fluid does not restrict the maximum heat flux attainable through a stainless steel circular tube. If thermal stress is not a factor, helium can, under practical operating conditions, achieve heat fluxes comparable to boiling water systems. It is also evident, however, that thermal stresses must be considered carefully in any design and that this will limit the heat flux more often than the surface heat transfer. This is particularly true when the coolant passages are not heated symmetrically which is typically the case for fusion reactor first wall applications. 


\section{REFERENCES}

1. M. Roberts et a1., Oak Ridge Experimental Power Reactor Study - 1976. ORNL-TM-5572, Oak Ridge Nationa1 Laboratory, Oak Ridge, TN 37830, August 1976.

2. C. C. Baker et al., Experimental Fusion Power Reactor Conceptual Design Study. GA-A-1400, Genera1 Atcmic Company, San Diego, CA 92138, JuTy 1976.

3. B. Badger et a1., UWMAK-II: A Conceptual Tokamak Power Reactor Design. UWFDM-112, University of Wisconsin, Madison, WI 53706, October 1975.

4. W. C. Wolkenhauer et a1., Status Report: Mirror Hybrid Reactor Studies. BNWL-1835, Batte11e, Pacific Northwest Laboratories, Richland, WA 99352, November 1974.

5. G. R. Hopkins and G. Melese-d'Hospital, "Helium Cooling of Fusion Reactors," Nuclear Engineering and Design. 26:215-230, 1974.

6. ASME Boiler and Pressure Vessel Code, Section VIII, Division 2, 1974. 


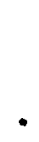

•. 
APPENDIX A

FLUID TEMPERATURE AND PRESSURE

DROP COMPUTATION PROCEDURE 
APPENDIX A. Fluid Temperature and Pressure Drop Computation Procedure.

Consider a uniformly heated horizontal straight duct, as shown in Figure A-1, through which a cooling fluid is driven by a limited pressure head and pumping power. The following assumptions are made:

- Fluid velocity is sufficiently low that sonic effects can be neglected.

- Frictional heating is ignored as insignificant compared to wall heat transfer.

- The total pressure drop is sufficiently small compared to the exit pressure that only density change due to heating need be considered.

Under these assumptions, the one dimensional conservation equations for mass, momentum and energy in the steady state are:

$\underline{\text { mass }}$

$$
\rho V \equiv G=\text { constant }
$$

momentum

$$
g \Delta P=\frac{1}{2} \frac{f G^{2}}{D_{h}} \int_{0}^{L} \frac{1}{\rho} d x+G^{2}\left(\frac{1}{\rho_{L}}-\frac{1}{\rho_{0}}\right)
$$

energy

$$
T=T_{0}+\frac{q^{\prime \prime} P_{h} x}{G A C_{p}}
$$

where $f$ is the wall friction factor, $D_{h}$ is the hydraulic diameter, $q$ " is the surface heat flux, $P_{h}$ is the heated perimeter and $C_{p}$ is the fluid specific heat. In addition to equations $A-1, A-2$ and $A-3$ an equation of state for the fluid is necessary to relate the density to temperature and pressure

$$
\rho=\rho(T, P)
$$




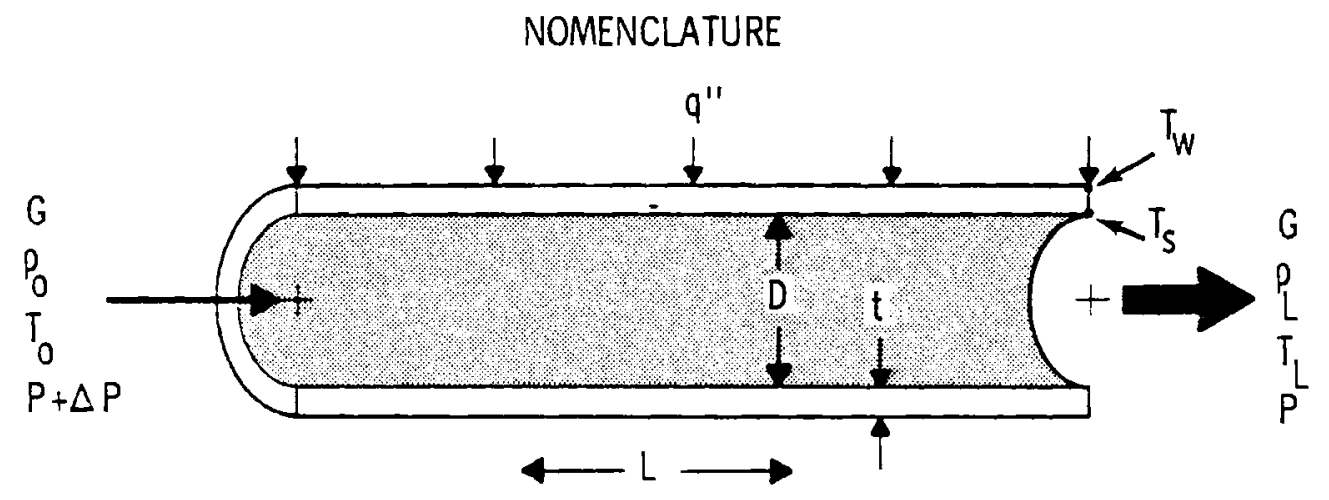

TEMPERATURE PROFILE

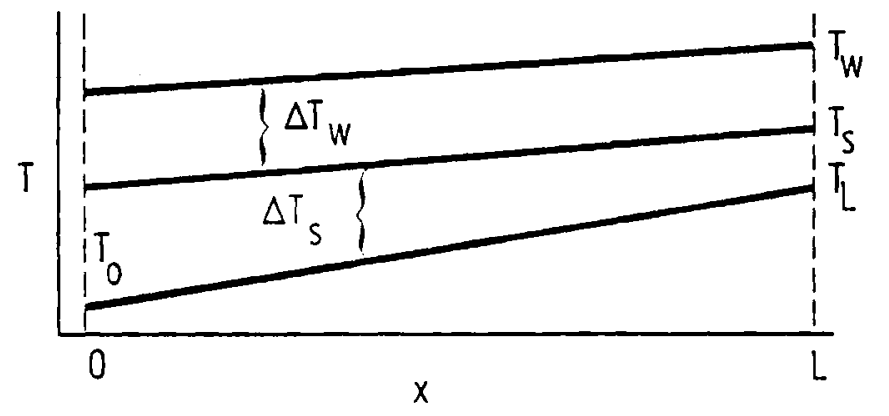

$$
\begin{aligned}
& \Delta T_{W}=\frac{q^{\prime \prime} P_{n}}{2 \pi k} \ln \left(1+\frac{2 t}{D}\right) \\
& \Delta T_{S}=\frac{q^{\prime \prime} \Delta T}{H} S
\end{aligned}
$$

FIGURE A-1. Geometry and Temperature Variation for an Externally Heated Tube 
We need to devise a computation procedure that relates the mass flux, $G$, and duct length, $L$, to the given operating conditions and limits. First, an expression for $G$ as a function of $\Delta P, L$ and $q "$ will be developed.

For a low pressure drop the change in density with pressure is small compared to the change due to heating. If the equation of state is linear at a constant pressure, the change in density along the duct is

$$
\rho-\rho_{0}=\left.\frac{\partial \rho}{\partial T}\right|_{P}\left(T-T_{0}\right)
$$

or, in terms of specific volume

$$
\frac{1}{\rho}-\frac{1}{\rho_{0}}=\left.\frac{\partial 1 / \rho}{\partial T}\right|_{P}\left(T-T_{0}\right)
$$

After the energy equation, A-3, is substituted for the temperature difference, equation $A-5$ is used to provide an expression for the specific volumes in the momentum equation, $A-2$, to yield:

$$
\begin{aligned}
g \Delta P=\frac{1}{2} \frac{f G^{2}}{D_{h}} \int_{0}^{L}\left(\frac{1}{\rho_{0}}\right. & \left.+\left.\frac{\partial 1 / \rho}{\partial T}\right|_{P} \frac{q^{\prime \prime} P_{h}}{G A C_{P}} x\right) d x \\
& +\left.G^{2} \frac{\partial I / \rho}{\partial T}\right|_{P} \frac{q^{\prime \prime} P_{h}}{\text { AGC }_{P}}
\end{aligned}
$$

After performing the integration and solving for $G$ we have

$$
G=\left[\frac{g \Delta P \rho_{0}}{\left(\frac{f L}{2 D_{h}}+\left.\frac{\partial T / \rho}{\partial T}\right|_{P} \rho_{0}\left(T_{L}-T_{0}\right)\left[\frac{f L}{4 D_{h}}+1\right]\right)}\right]^{1 / 2}
$$

Given the temperatures, $q^{\prime \prime}$ and $\Delta P$, the length, $L$, and friction factor, $f$, are functions of $G$. An iterative solution is therefore necessary. The solution procedure is as follows: 
1. Calculate the maximum surface temperature, $T_{S}$, given the wall thickness, heat flux and maximum duct wall temperature, $\mathrm{T}_{\mathrm{W}}$.

$$
T_{S}=T_{w}-\frac{q^{\prime \prime} P_{h}}{2 \pi K} \ln \left(1+\frac{2 t}{D}\right)
$$

Note that the wall thickness and heat flux are computed by means of the expressions derived in Appendix B. The maximum surface temperature may also be specified directly. See Figure $A-1$.

2. Compute the friction factor and heat transfer coefficient, $H$, by appropriate correlation using either an initial guess for $G$ or the last iterate value.

3. Compute the fluid exit, $T_{L}$, temperature required to make the duct surface temperature $T_{S}$

$$
T_{L}=T_{S}-\frac{q^{\prime \prime}}{H}
$$

4. Calculate the duct length required to raise the fluid temperature from $T_{0}$ to $T_{L}$ at the current $G$

$$
L=\left(T_{L}-T_{0}\right) \frac{G A C_{P}}{q^{\prime \prime} P_{h}}
$$

If the length is negative, stop.

5. Check the given pressure head, $\Delta P_{0}$, against the pumping power limit, $\psi$, which is defined as a fraction of the total heat input to the duct.

$$
\Delta P=\min \left(\Delta P_{0}, \frac{\rho_{0} \psi q " P_{h} L J}{G A}\right)
$$

6. Calculate the new mass flux with equation $A-7$ and check for convergence. If the change in $G$ is too large, return to step 1 and repeat. 
APPENDIX B

THERMAL STRESS LIMITS ON HEAT FLUX 
APPENDIX B. Thermal Stress Limits on Heat Flux

The wall of a coolant tube has a minimum thickness required to support the internal coolant pressure and remain below the ASME allowable design stress, $\sigma_{m}$.

For thin tubes this thickness is expressed as

$$
t=\frac{P D}{2 \sigma_{m}}
$$

where $P$ is the internal pressure and $D$ is the tube inside diameter.

If the tube is cooled uniformly on the inner surface, the temperature gradient across the wall gives rise to an additional tangential and axial tensile stress at the inner surface and a corresponding compressive stress on the outside, as shown in Figure B-1. The stress $\sigma_{t}$ is computed by

$$
\sigma_{t}=\frac{E \alpha \Delta T}{2(1-v) \ln \left(1+\frac{2 t}{D}\right)}\left[\frac{2 \ln \left(1+\frac{2 t}{D}\right)}{1-\frac{1}{\left(1+\frac{2 T}{D}\right)^{2}}}-1\right]
$$

where $E$ is Young's modulus, $\alpha$ is the linear thermal expansion coefficient and $\nu$ is Poisson's ratio. ${ }^{(5)}$ If the thickness is prescribed by the internal pressure via equation $B-1$, the wall temperature gradient and, therefore, heat flux, is limited by the maximum allowable thermal stress.

The combination of the pressure stress and thermal stress is limited to three times $\sigma_{m}$. Since the wall thickness is chosen to make the pressure stress exactly $\sigma_{m}$, the condition on thermal stress is $\sigma_{t}>2 \sigma_{m}$. Substituting equation B-1 for the ratio of thickness to diameter in equation for $B-2$ and solving for the temperature gradient yields:

$$
\Delta T=\frac{4(1-v) \ln \left(1+\frac{P}{\sigma_{m}}\right) \sigma_{m}}{E \alpha\left[\frac{2 \ln \left(1+P / \sigma_{m}\right)}{\left.1-\frac{1}{\left(1+P / \sigma_{m}\right.}\right)}-1\right]}
$$



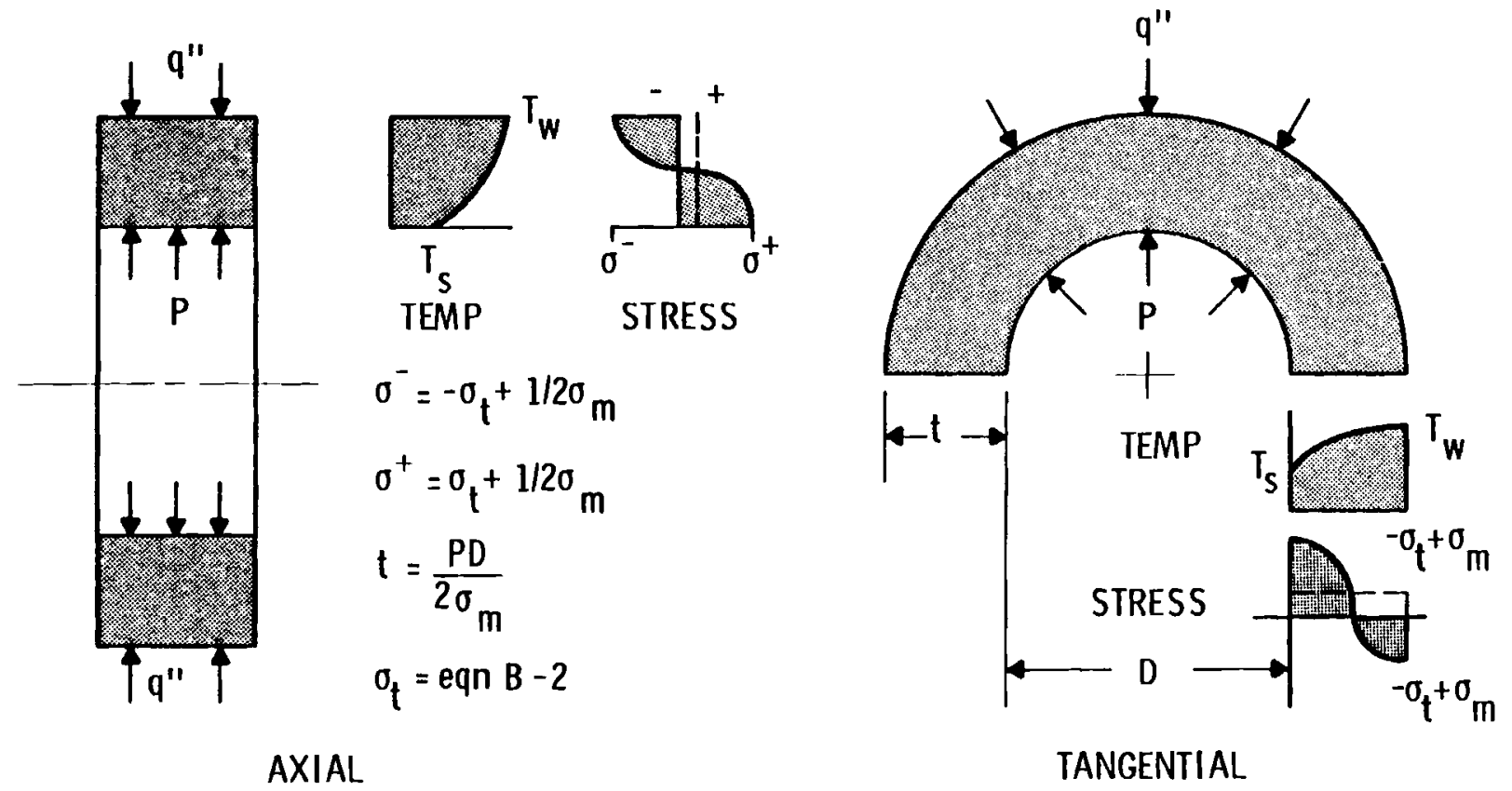

FIGURE B-1. Temperatures and Stresses for a Uniformly Heated Tube 
The temperature difference is related to the heat flux through

$$
\Delta T=\frac{q^{\prime \prime} P_{h}}{2 \pi K} \ln \left(1+\frac{2 t}{D}\right)
$$

The heat flux 7 imit follows by substituting equation B-4 into equation B-3 and solving for $q "$ ".

$$
q^{\prime \prime}=\frac{8 \pi K \sigma_{m}(1-v)}{E \alpha P_{h}\left[\frac{2 \ln \left(1+P / \sigma_{m}\right)}{1-\frac{1}{\left(1+P / \sigma_{m}\right)^{2}}}-1\right]}
$$

Equation B-5 prescribes the steady state heat flux limit due to thermal and pressure stresses. Since most proposed CTR devices operate in a cyclic mode in which the temperature gradient may change from a maximum value to near zero every few minutes, thermal fatigue is also an important consideration.

The heat flux limit for thermal fatigue may be determined by setting half the stress given by eqation B-2 to maximum cyclic stress for infinite life (or some specified number of cycles), $\sigma_{f}$, at the average wall temperature. Temperature effects are incorporated by adjusting $\sigma_{f}$ by the ratio of Young's moduli. Equation B-1 and B-4 are substituted for the thickness to diameter ratio and temperature difference, respectively, so that

$$
q_{f}^{\prime \prime}=\frac{8 \operatorname{mk\sigma }_{f}(1-v)}{\operatorname{E\alpha P}\left[\frac{2 \ln \left(1+P / \sigma_{m}\right)}{\left.1-\frac{1}{\left(1+P / \sigma_{m}\right)^{2}}-1\right]}\right.}
$$

Note that since $q_{f}^{\prime \prime}=\left(\sigma_{f} q^{\prime \prime}\right) / \sigma_{m}$, fatigue will usually prescribe the minimum heat flux since $\sigma_{f}<\sigma_{m}$ for stainless steel.

If the coolant tube surface is non-symmetrically heated as in a first wall application, an additional thermal stress occurs from one side of the tube being hotter than the other. A conservative "worst case", where half 
the tube perimeter is heated and the other half is at the coolant exit temperature, will be considered. This is illustrated in Figure B-2.

The axial thermal stress $\sigma_{a}$ at any position can be calculated by a simple beam model constrained in bending but free axially as

$$
\sigma_{a}=-E \alpha(T-\bar{T})
$$

where $T$ is the local temperature and $\bar{T}$ is the average temperature over the cross section. Assuming that the cold half of the tube is at the fluid exit temperature, $T_{L}$, the cross section average is

$$
\bar{T}=\frac{1}{2}\left(\frac{1}{2} T_{W}+\frac{1}{2} T_{S}+T_{L}\right)
$$

where $T_{W}$ and $T_{S}$ are the hot side outer and inner surface temperatures, respectively.

The temperature difference in equation B-7 is significant at the outer and inner surfaces on the hot side and on the cold side where the tube wall temperatures are $T_{W}, T_{S}$, and $T_{L}$ respectively. The relations between these temperatures and the heat flux in Equations $A-8$ and $A-9$ are utilized to relate the axial thermal stress to heat flux at each of the three locations. These are summarized in Table B-1.

The axial thermal stress due to the radial temperature gradient from equation B-2 and the axial internal pressure stress must also be included. The absolute value of the sum of the three stresses must be less than three times $\sigma_{m}$ as in the previous uniformly heated case. When this condition is reached the axial pressure, which is only $1 / 2 \sigma_{m}$, is small compared to the thermal stresses which then determine the sign of the sum. In addition, if fatigue is to be considered, half the sum of the axial thermal stress components must be less than the maximum cycle stress for the infinite life (or specified number of cycles), $\sigma_{f}$.

The above four stress limiting conditions are solved for the heat flux in the same manner as equations $B-5$ and $B-6$ previously. The results are shown in Table $B-2$. 

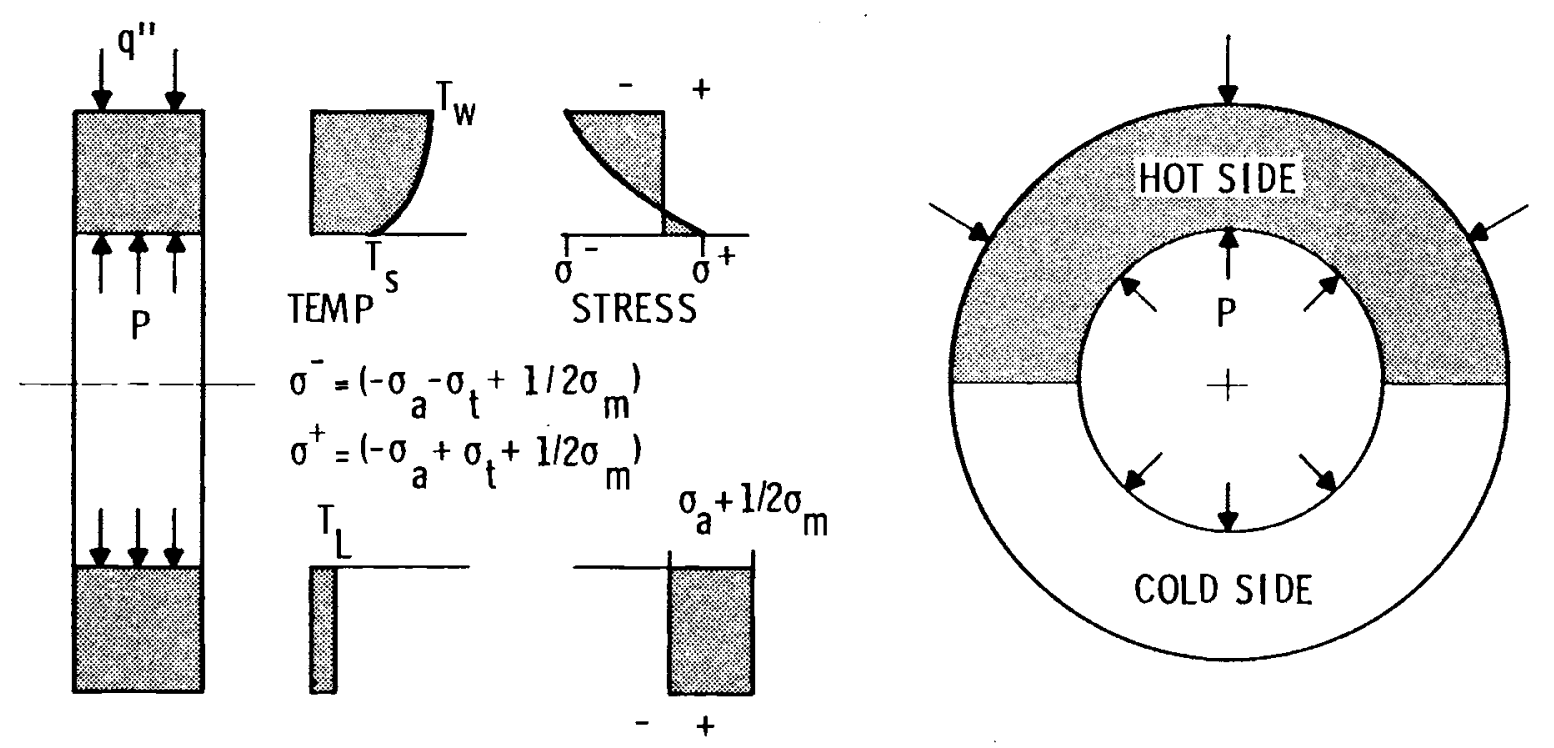

$$
\begin{aligned}
& \sigma_{t}=\operatorname{eqn} B-2 \\
& \sigma_{a}=\operatorname{eqn} B-7
\end{aligned}
$$

FIGURE B-2. Temperatures and Stresses for a Non-Symmetrically Heated Tube 
TABLE B-1. Expressions for Axial Thermal Stress

\begin{tabular}{|c|c|c|}
\hline Location & $\begin{array}{c}\text { Tube } \\
\text { Temperature, } T\end{array}$ & $\begin{array}{l}\text { Stress } \\
\sigma_{a}=-E \alpha(T-\bar{T})\end{array}$ \\
\hline $\begin{array}{l}\text { Outer Surface, } \\
\text { hot side }\end{array}$ & $T_{W}$ & $-\frac{E \alpha q^{\prime \prime}}{2}\left[\frac{3 P}{4 \pi K} \ln \left(1+\frac{P}{\sigma_{m}}\right)+\frac{1}{H}\right.$ \\
\hline $\begin{array}{l}\text { Inner Surface, } \\
\text { hot side }\end{array}$ & $T_{s}=T_{w}-$ & $\iota$ \\
\hline & $\frac{q^{\prime \prime} P}{2 \pi K} \ln \left(1+\frac{P}{\sigma_{m}}\right)$ & $-\frac{E \alpha q^{\prime \prime}}{2}\left[\frac{-P h}{4 \pi K} \ln \left(1+\frac{P}{\sigma_{m}}\right)+\frac{1}{H}\right]$ \\
\hline Cold Side & $T_{L}=T_{S}-\frac{q^{\prime \prime}}{H}$ & $+\frac{E \alpha q^{\prime \prime}}{2}\left[\frac{P_{h}}{4 \pi K} \ln \left(1+\frac{P}{\sigma_{m}}\right)+\frac{1}{H}\right]$ \\
\hline
\end{tabular}

TABLE B-2. Summary of Heat Flux Limits for a Non-symmetrical Heated Tube

\section{Limit and Location \\ Outer surface hot side}

Compression

Fatigue

$$
q_{f}<\frac{4 \sigma_{f}}{E \alpha\left(\frac{1}{H}+\frac{P h}{2 \pi K}\left[\frac{3}{2} \ln \left(1+\frac{P}{\sigma_{m}}\right)+\frac{B}{1-v}\right]\right)}
$$

Inner surface hot side tension

$$
q_{i t}<\frac{5 \sigma_{m}}{E \alpha\left(\frac{P_{h}}{2 \pi K}\left[\frac{1}{2} \ln \left(1+\frac{P}{\sigma_{m}}\right)+\frac{B}{1-v}\right]-\frac{1}{H}\right)}
$$

Cold side tension

\section{Expression}

$$
q_{o c}<\frac{7 \sigma_{m}}{E \alpha\left(\frac{1}{H}+\frac{P h}{2 \pi K} \frac{3}{2}\left[\ln \left(1+\frac{P}{\sigma_{m}}\right)+\frac{B}{1-\nu}\right]\right)}
$$

$$
q_{c t}<\frac{5 \sigma_{m}}{E \alpha\left[\frac{1}{H}+\frac{P_{h}}{4 \pi K} \ln \left(1+\frac{P}{\sigma_{m}}\right)\right]}
$$

$$
\text { B-6 }
$$




$$
B=\left[\frac{2 \ln \left(1+\frac{P}{\sigma_{m}}\right)}{1-\frac{1}{\left[1+\frac{P}{\sigma_{m}}\right]^{2}}}-1\right]
$$

Since $q_{f}=\left[\left(4 \sigma_{f}\right) /\left(7 \sigma_{m}\right)\right] q_{o c}$ fatigue is even more likely to be limiting for the non-symmetrically heated tube. If fatigue is not considered, sensitivity analysis shows that $q_{O C}$ will be the minimum at all but very low pressures where $q_{c t}$ becomes limiting. $q_{i t}$ is not a significant limit because of the cancellation of compressive and tensile stresses. 


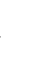




\section{DISTRIBUTION}

No. of

Copies

OFFSITE

A. A. Churm

DOE Chicago Patent Group

9800 S. Cass Ave.

Argonne, IL 60439

J. M. Williams

DOE Division of Magnetic

Fusion Energy

Washington, DC 20545

3 F. E. Coffman

DOE Division of Magnetic

Fusion Energy

Washington, DC 20545

K. M. Zwilsky

DOE Division of Magnetic

Fusion Energy

Washington, DC 20545

J. Baublitz

DOE Division of Magnetic

Fusion Energy

Washington, DC 20545

J. W. Beal

DOE Division of Magnetic Fusion Energy Washington, DC 20545

$5 \quad$ L. Bogart

DOE Division of Magnetic

Fusion Energy

Washington, DC 20545

M. M. Cohen

DOE Division of Magnetic

Fusion Energy

Washington, DC 20545

H. S. Cullingford

DOE Division of Magnetic

Fusion Energy

Washington, DC 20545
No. of

Copies

E. N. C. Dalder

DOE Division of Magnetic

Fusion Energy

Washington, DC 20545

J. F. Decker

DOE Division of Magnetic

Fusion Energy

Washington, DC 20545

C. R. Finfgeld

DOE Division of Magnetic

Fusion Energy

Washington, DC 20545

J. N. Grace

DOE Division of Magnetic

Fusion Energy

Washington, DC 20545

E. E. Kintner

DOE Division of Magnetic

Fusion Energy

Washington, DC 20545

R. N. Kostoff

DOE Division of Magnetic

Fusion Energy

Washington, DC 20545

J. V. Martinez

DOE Division of Magnetic

Fusion Energy

Washington, DC 20545

J. 0. Neff

DOE Division of Magnetic

Fusion Energy

Washington, DC 20545

T. C. Reuther

DOE Division of Magnetic

Fusion Energy

Washington, DC 20545 
No. of

Copies

5 C. R. Head

DOE Division of Magnetic

Fusion Energy

Washington, DC 20545

$P$. M. Stone

DOE Applied Plasma

Physics Program

Washington, DC 20545

Assistant Director for

Technology

DOE Divison of Reactor

Research and Development

Washington, DC 20545

Chief, Fuel Systems Branch

DOE Division of Reactor

Research and Development

Washington, DC 20545

27 DOE Technical Information

Center

2 Director, ANL Fusion Power

Program, Building 208

Argonne National Laboratory

9700 S. Cass Ave.

Argonne, IL 60439

M. S. Kaminsky

Argonne National Laboratory

9700 S. Cass Ave.

Argonne, IL 60439

V. H. Maroni

Argonne National Laboratory

9700 S. Cass Ave.

Argonne, IL 60439

P. M. Persiani

Argonne National Laboratory

9700 S. Cass Ave.

Argonne, IL 60439
No. of

Copies

M. Petrick

Engineering and Technology

Division

Argonne National Laboratory

9700 S. Cass Ave.

Argonne, IL 60439

W. E. Parkins, Manager

Atomics International

Component Engineering and

Technology Division

North American Rockwell

P.0. Box 309

Canoga Park, CA 91304

2 Chairman, Department of Applied Sciences

Brookhaven National Laboratory

Associated Universities

Upton, NY 11973

Associate Chairman for

Chemistry and Materials

Programs, Department of

Applied Sciences

Brookhaven National Laboratory Associated Universities

Upton, NY 11973

A. N. Goland

Brookhaven National Laboratory

Associated Universities

Upton, NY 11973

D. Gurinsky

Brookhaven National Laboratory

DOE Brookhaven Area Office

Upton, NY 11973

S. Pearlstein

Brookhaven National Laboratory

DOE Brookhaven Area Office

Upton, NY 11973

J. R. Powell

Brookhaven National Laboratory DOE Brookhaven Area Office Upton, NY 11973 
No. of

Copies

A. J. Impink, Jr.

Carnegie Mellon University

Pittsburgh, PA 15213

R. A. Gross

Columbia University

Plasma Physics Laboratory

236 SW Mudd Bldg.

New York, NY 10027

Program Manager for

Fusion Power

Electric Power Research

Institute

3412 Hillview Ave.

Palo Alto, CA 94304

W. C. Gough

Electric Power Research Institute

3412 Hillview Ave.

Palo Alto, CA 94303

2 Manager, Fusion Engineering Department

Gulf General Atomic Co.

P.0. Box 81608

San Diego, CA 92138

G. R. Hopkins

Gulf General Atomic Co.

P.0. Box 81608

San Diego, CA 92138

Z. Sabri

Nuclear Engineering Department

261 Sweeney $\mathrm{Hall}$

Iowa State University

Ames, IA 50010

H. K. Forsen

Jersey Nuclear Company

777 106th Ave., NE

Bellevue, WA 98004
No. of

Copies

R. Borg

Lawrence Livermore Laboratory

P.0. Box 808

Livermore, CA 94550

T. K. Fowler

Lawrence Livermore Laboratory

P.0. Box 808

Livermore, CA 94550

A. C. Haussmann

Lawrence Livermore Laboratory

P.0. Box 808

Livermore, CA 94550

A. L. Hunt

Lawrence Livermore Laboratory

P.0. Box 808

Livermore, CA 94550

R. Moir

Lawrence Livermore Laboratory

P.0. Box 808

Livermore, CA 94550

C. J. Taylor

Lawrence Livermore Laboratory

P. 0. Box 808

Livermore, CA 94550

L. L. Wood

Lawrence Livermore Laboratory

P. 0 . Box 808

Livermore, CA 94550

Division Leader, CTR Division

Los Alamos Scientific Laboratory

P.0. Box 1663

Los Alamos, NM 87544

D. J. Dudziak

Los Alamos Scientific Laboratory

P.0. Box 1663

Los Alamos, NM 87544 
No. of

Copies

D. B. Henderson

Los Alamos Scientific Laboratory

CTR Division

P.0. Box 1663

Los Alamos, NM 87544

L. Stewart

Los Alamos Scientific Laboratory

CTR Division

P.0. Box 1663

Los Alamos, NM 87544

B. Coppi

Department of Physics

Massachusetts Institute of

Technology

Cambridge, MA 02739

0. K. Harling

Massachusetts Institute of

Technology

Cambridge, MA 02139

L. Lidsky

Department of Nuclear

Engineering

Massachusetts Institute of

Technology

Cambridge, MA 02139

D. Rose

Massachusetts Institute of

Technology

Cambridge, MA 02139

R. E. Stickney

Mechanical Engineering

Massachusetts Institute of

Technology

Cambridge, MA 02139

Manager, Technology

Applications and Development

Mound Laboratory

P.0. Box 32

Miamisburg, $\mathrm{OH} 45342$
No. of

Copies

J. J. Reinmann

NASA--Lewis Research Center

2100 Brookpark Rd.

Cleveland, $\mathrm{OH} 44135$

V. Arp

National Bureau of Standards

Cryogenics Division

Boulder, CO 80302

Director, Metals and Ceramics

Division

Oak Ridge National Laboratory

P.0. Box $Y$

Oak Ridge, TN 37830

Program Manager, Fusion

Reactor Technology Program

B1dg. 9204-1

Oak Ridge National Laboratory

P.0. Box $Y$

Oak Ridge, TN 37830

J. L. Scott, Manager

Magnetic Fusion Energy

Materials

Metals and Ceramics Division

B7dg. 4500 SM, S-178

P. 0. Box $X$

Oak Ridge, TN 37830

A. P. Fraas

Oak Ridge National Laboratory

P.0. Box $Y$

Oak Ridge, TN 37830

J. Rand McNal7y, Jr.

Oak Ridge National Laboratory

P.0. Box $Y$

Oak Ridge, TN 37830

D. Steiner

Oak Ridge National Laboratory

P.0. Box $Y$

Oak Ridge, TN 37830 
R. Werner

Oak Ridge National Laboratory

P.0. Box $X$

Oak Ridge, TN 37830

R. Cooper

Physics International

2700 Merced St.

San Leandro, CA 94577

R. A. Huse

Public Service Electric and Gas Co.

80 Park Place

Newark, NJ 07101

H. Perkins

Department of Chemistry

Princeton University

Princeton, NJ 06540

Director, Plasma Physics Laboratory

Princeton University

Box 451

Princeton, NJ 08540

Project Manager, TFTR

Plasma Physics Laboratory

Princeton University

Box 451

Princeton, NJ 08540

R. G. Mills

Plasma Physics Laboratory

Princeton University

Box 451

Princeton, NJ 08540

E. C. Tanner

Plasma Physics Laboratory

Princeton University

Box 451

Princeton, NJ 08540
3 F. H. Tenney

Plasma Physics Laboratory

Princeton University

Box 451

Princeton, NJ 08540

2 W. Bauer

Division Supervisor of

Physical Research

Sandia Laboratories

Livermore, CA 94550

M. Kristiansen

Texas Tech. University

Lubbock, TX 79409

A. F. Haught

United Aircraft Research

Laboratory

United Aircraft Corp.

East Hartford, CT 06108

Head, Thermo Structural

Materials Branch

U.S. Naval Research Laboratory

Metallurgy Division

Code 6390

Washington, DC 20390

L. Levine

U.S. Naval Research Laboratory

Washington, DC 20390

C. Z. Serpan, Jr.

U.S. Naval Research Laboratory

Washington, DC 20390

F. Chen

UCLA School of Engineering and Applied Science

Boelter 7731

Los Angeles, CA 90024

A. J. Lichtenberg University of California

Electronics Research Laboratory

College of Engineering

Berkeley, CA 94720 
C. D. Hendricks

University of Illinois

Nuclear Engineering Laboratory

Urbana, IL 61801

T. Kamash

University of Michigan

Nuclear Engineering Department

Ann Arbor, MI 48105

Dean Abrahamson

University of Minnesota

School of Public Affairs

Social Science Building/308

Minneapolis, MN 55455

W. G. Davey

University of Texas

Department of Physics

Austin, TX 78712

E. L. Draper, Jr. University of Texas

Department of Physics

Austin, TX 78712

W. E. Drummond

University of Texas

Department of Physics

Austin, TX 78712

A. Hertzberg

University of Washington

Aerospace Research Laboratory

316 Guggenheim

Seattle, WA 98105

A. L. Babb

University of Washington

Nuclear Engineering Department

Seattle, WA 92105

R. Conn

University of Wisconsin

Nuclear Engineering Department

Madison, WI 53706
G. L. Kulcinski

University of Wisconsin

Nuclear Engineering Department

Madison, WI 53706

C. W. Maynard

University of Wiscons in

Nuclear Engineering Department

Madison, WI 53706

D. Lichtman

Department of Physics

University of Wisconsin

Milwaukee, WI 53201

E. E. Donaldson

Washington State University

Department of Physics

Pullman, WA 99163

Manager, Fusion Power Systems

Department

Westinghouse Electric Corp.

P.0. Box 355

Pittsburgh, PA 15230

ONSITE

3 ERDA Richland Operations Office

W. A. Burns

P. G. Holsted

H. E. Ransom

Rockwell Hanford Operations

J. D. Kaser

3 Hanford Engineering Development Laboratory

Manager, Materials Engineering

D. G. Doran

H. H. Yoshikawa 
No. of

Copies

79 Battelle-Northwest

DT Aase

L Ault

DR Baer

MCC Bampton

WE Bickford

$\mathrm{SH}$ Bush

RA Busch

NE Carter

DB Cearlock

TD Chikalla

WJ Coleman

SD Dahlgren

DE Deonigi

DA Dingee

CE Elderkin

RM Fleischman

JC Fox

RF Foster

JJ Fuquay

HR Gardner

WJ Gray

AJ Haverfield

US Hartman

JA Hebert

FP Hungate

$A B$ Johnson, Jr.

$\mathrm{RH}$ Jones

TJ Kabele

$N$ Laegreid

BR Leonard

RC Liikala

D Mahlum

RP Marsha 11

ED MCClanahan

JL McElroy

JM Nielsen

RE Nightingale

DE Olesen

NJ 01 son

JF Park

RW Perkins
RT Perry

LT Pedersen

$\checkmark$ Rasberry

LC Schmid

DB Shipler

EP Simonen

CL Simpson

CW Stewart (10)

RW Stewart

DL Styris

AM Sutey (3)

WL Templeton

VL Teofilo

JK Thompson

MT Thomas

GL Tingey

$M$ Vagins

BE Vaughan

WR Wiley

HJ Willenberg

TL Willke

Technical Information (5)

Technical Publications 
. 